\title{
Pattern of mandibular fractures and helmet use among motorcycle crash victims in Tanzania
}

\author{
Jeremiah Robert Moshy ${ }^{1}$, Beatus Stanslaus Msemakweli², Sira Stanslaus Owibingire ${ }^{1}$, Karpal Singh Sohal ${ }^{1}$
}

1. Department of oral and maxillofacial surgery, Muhimbili University of Health and Allied Sciences.

Dar es Salaam, Tanzania.

2. Department of dental services, Mount Meru Regional Referral Hospital. Arusha, Tanzania.

\section{Emails of the authors:}

Jeremiah R Moshy (jeremiah.moshy@yahoo.com); Beatus S Msemakweli (stanbeatus@gmail.com);

Sira S Owibingire (siraowibingire@gmail.com); Karpal Singh Sohal (karpal@live.com)

\begin{abstract}
Background: The maxillofacial structures are commonly affected in motorcycle crashes, with the mandible being one of the most frequently fractured bones. Helmets have been shown to have a protective effect in preventing maxillofacial injuries, however, its effect on the occurrence of mandibular fractures is not very well established.

Objectives: To evaluate the pattern of mandibular fractures among motorcycle crash victims in Tanzania, and determine the role of helmets in occurrence of mandibular fractures among the motorcyclists.

Methodology: This was a 6-months prospective, cross-sectional study that recruited motorcycle crash victims who reported with mandibular fractures following motorcycle crash at Muhimbili National Hospital. A specially designed questionnaire was used for data collection. For purpose of analysis, the Statistical Package for Social Sciences software version 20 was used. Results: The study included a total of 132 participants of whom majority were male (120, 90.9\%). The peak age incidence was $21-40$ years in $76.5 \%$ of the victims. More than half $(89,67.4 \%)$ of the victims were riders during the crash. Helmet use was reported in $42.3 \%$ of the victims, and majority $(67.3 \%)$ were usinghalf-face helmets. The symphysis region was the frequently fractured anatomical location $(50,37.9 \%)$. More than half of the victims had multiple site involvement, with higher odds observed in individuals wearing half-face helmets.

Conclusion: Young males were affected ten times more than females. Most of the victims were riders during the crash. The symphysis region was the frequently fractured anatomical site. There was no difference in occurrence of mandibular fractures between those who wore and those who did not wear helmets during the crashes. However, the severity of mandibular fractures was dependent on the type of helmet used.

Keywords: Mandibular fracture; motorcycle crash; helmet use; Tanzania.

DOI: https://doi.org/10.4314/ahs.v20i2.32

Cite as: Moshy JR, Msemakweli BS, Owibingire SS, Sohal KS. Pattern of mandibular fractures and helmet use among motorcycle crash victims in Tanzania. Afri Health Sci. 2020; 20(2): 789-797. bttps:// doi.org/10.4314/abs.v20i2.32
\end{abstract}

\section{Introduction}

Motorcycle crashes represent an epidemic for current societies in the developing world, and have become a public health concern considering the rate of morbidity

\section{Corresponding author:}

Karpal Singh Sohal,

Department of Oral and maxillofacial surgery,

Muhimbili University of Health and Allied Sciences.

Dar es Salaam, Tanzania.

P.O. Box 65014 Dar es Salaam, Tanzania.

Telephone: +255712723917

Email:karpal@live.com and mortality it causes ${ }^{1}$. In recent years, motorcycles have become a common means of transport in many parts of Tanzania, be it in a rural or urban settings ${ }^{2}$. The incidence of motorcycle crashes depends on a multitude of factors including but not limited to, road conditions, riders' attitude and possible use of alcohol and illicit drugs ${ }^{3,4}$.

The maxillofacial region is vulnerable to varying degree of injuries since it is the most exposed parts of the human body ${ }^{2}$. As such, the maxillofacial structures are commonly affected by motorcycle crashes, with the mandible being one of the most frequently fractured bones $^{5,6}$. Helmets have been shown to have a protective effect in preventing maxillofacial injuries ${ }^{7}$, however, 
its effect on occurrence of mandibular fractures is not very well established.

Trauma epidemiology is essential to describe the morbidity, disability and limitations, as well as defining the most important target for prevention regarding the severity of the injury ${ }^{8}$. Although fractures of the mandible are usually not immediately life-threatening, they can cause considerable functional and esthetic problems to the patients, requiring treatment that can place additional burden on health centers ${ }^{7}$.

Since motorcycle injuries contribute a substantial number of hospital admissions and deaths in Tanzania, this study aimed at evaluating the pattern of mandibular fractures among motorcycle crash victims in Tanzania, and determine the role of helmets in occurrence of mandibular fractures among the motorcyclists.

\section{Methodology}

This was a prospective cross-sectional study that recruited motorcycle crash victims who reported within a period of 6-months (July 2016 to January 2017) with mandibular fractures at Muhimbili National Hospital in Tanzania. The inclusion criteria included: presence of mandibular fracture, being involved in motorcycle crash either as a rider, pillion passenger or pedestrian. A convenient sampling method was used, and all cases fulfilling the criteria required for this study were included once they consented to participate in the study.

A specially designed questionnaire was used to obtain data on sociodemographic characteristics, patient's complaints, Status of the victim during accident, use of helmet and type of helmet used, use of alcohol by the rider, time of injury, anticipated speed of the motorbike during accident and nature of the road where accident occurred. The clinical findings from the patients were recorded in a special predesigned clinical form. Radiological investigations were ordered to aid in diagnosis.
The patients were divided into groups according to age by range of 20 years. The mandibular fractures were categorized as per anatomical sites of mandible. The severity/multiplicity of injury was classified into not severe/multiple (when only one site of mandible was fractured) and severe (when 2 or more sites of mandible had fractures).

For purpose of analysis, data were entered into the Statistical Package for Social Sciences software (SPSS) for windows (version 20, IBM Corporation Chicago, IL, USA). The actual age (in numerical form) was represented as the mean and standard deviation (SD) while the categorical variables were represented as frequencies and percentages together with the $95 \%$ confidence intervals wherever appropriate. The associations between mandibular fractures and motorcycle crash- related causes were analyzed using the Chi-square test for independence. All tests were two-tailed, with a P-value of 0.05 or less considered statistically significant. Univariate logistic regression was used to investigate the predictors of helmet use, and multiplicity of mandibular fractured sites.

The study was approved by the Institution Review Board of the Muhimbili University of Health and Allied Sciences (MUHAS). Permission to conduct the study was sought from the administration of MNH. The participants were assured of confidentiality but also their right to participate and right to withdraw without any conditions.

\section{Results}

The study included a total of 132 participants who had sustained fracture of the mandible following motorcycle crash. Majority of the victims were male (120, $90.9 \%$ ) with a male to female ratio of 10:1. The age of the victims ranged from 16 to 54 years with the mean age of $27.13 \pm 6.87$. The peak age incidence was $21-40$ years in $76.5 \%$ of the victims [Table 1]. 
Table 1: Sociodemographic characteristics, and circumstances during crash according to the status of the victim.

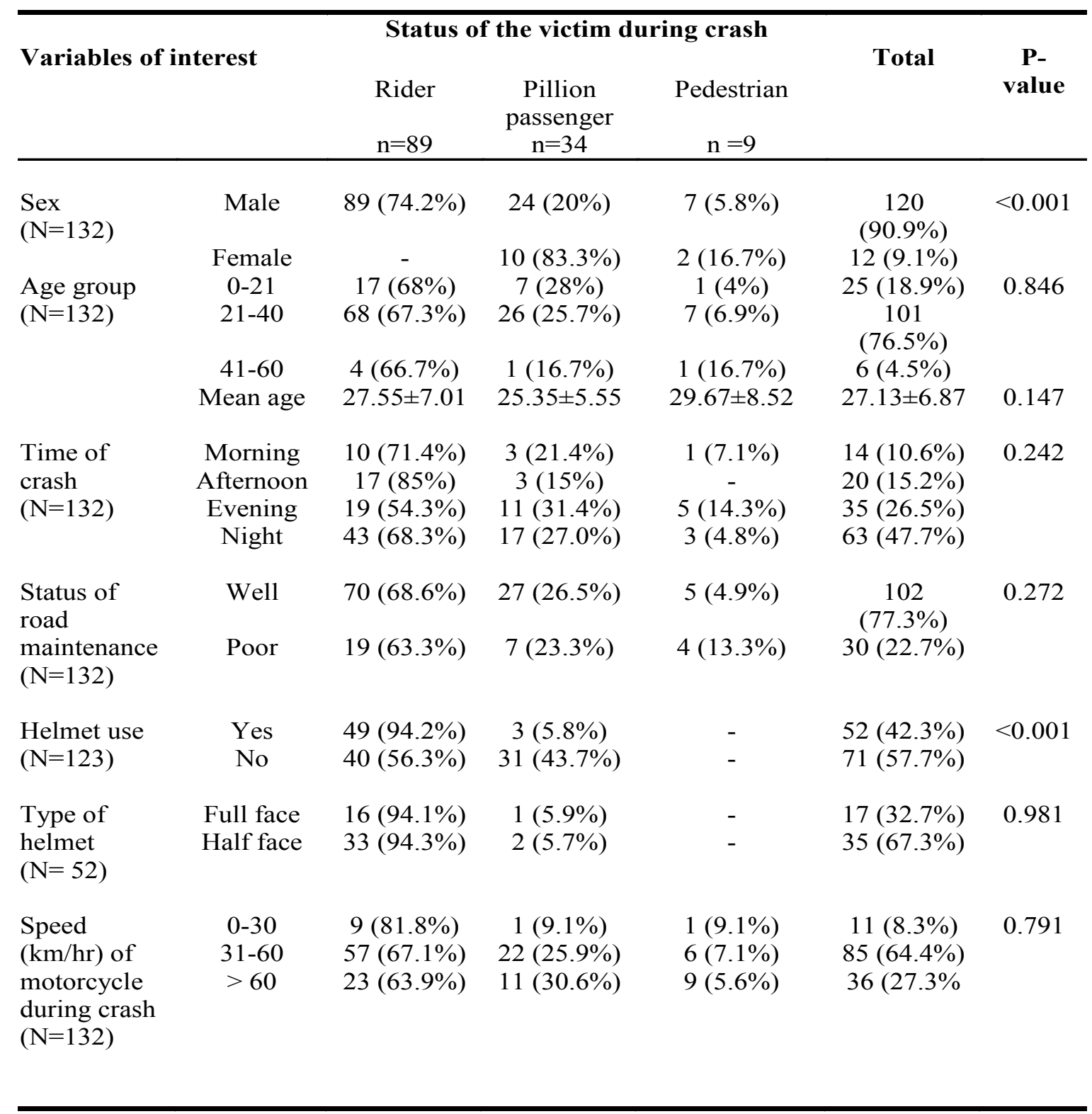

More than half $(89,67.4 \%)$ of the victims were riders during the crash. Almost one-third (40,30.3\%) of the motorcycle riders were reported to be under influence of alcohol at the time of the crash. Concerning the nature of the road during the crash, majority $(102,77.3 \%)$ were travelling on well-maintained roads. The motorcycle travel speed of $31-60 \mathrm{~km} /$ hour during crash was reported by most $(85,64.4 \%)$ of the victims. The crashes frequently occurred during nights $(63,47.7 \%)$ followed by evenings $(35,26.5 \%)$. Helmet use was reported in $42.3 \%$ of the victims, and majority $(35,67.3 \%)$ were using half-face helmets [Table 1].

More than half $(77,58.3 \%)$ of the victims were subsequently admitted following crash, while the remain- ing ones $(55,41.7 \%)$ were outpatients. The association between the sex of the victim, use of helmet and the status of the victim during crash was statistically significant $(p<0.001)$. Upon logistic analysis, the passengers had $92 \%$ lower odds of using helmets compared to riders $(\mathrm{OR}=0.08,95 \%$ CI $0.02-0.28)$.

The most common mode of crash was crash with a car $(49,37.2 \%)$ followed by crash with another motorcycle $(42,31.8 \%)$. Other modes included skidding (27, $20.5 \%)$ and motorcyclist hitting a wall/post (14,10.5\%).

There were a total of 196 fractured sites among the 132 patients. The most frequently fractured anatomical location of the mandible was the symphysis region (50, $37.9 \%$ ), while the least fractured site was the coronoid 
process $(2,1.5 \%)$. Number of sites of fractures ranged from 1 to 5 . Majority of the patients had multiple site involvement $(75,56.8 \%)$ compared to single site involvement $(57,43.2 \%)$ [Figure 1, Table 4].

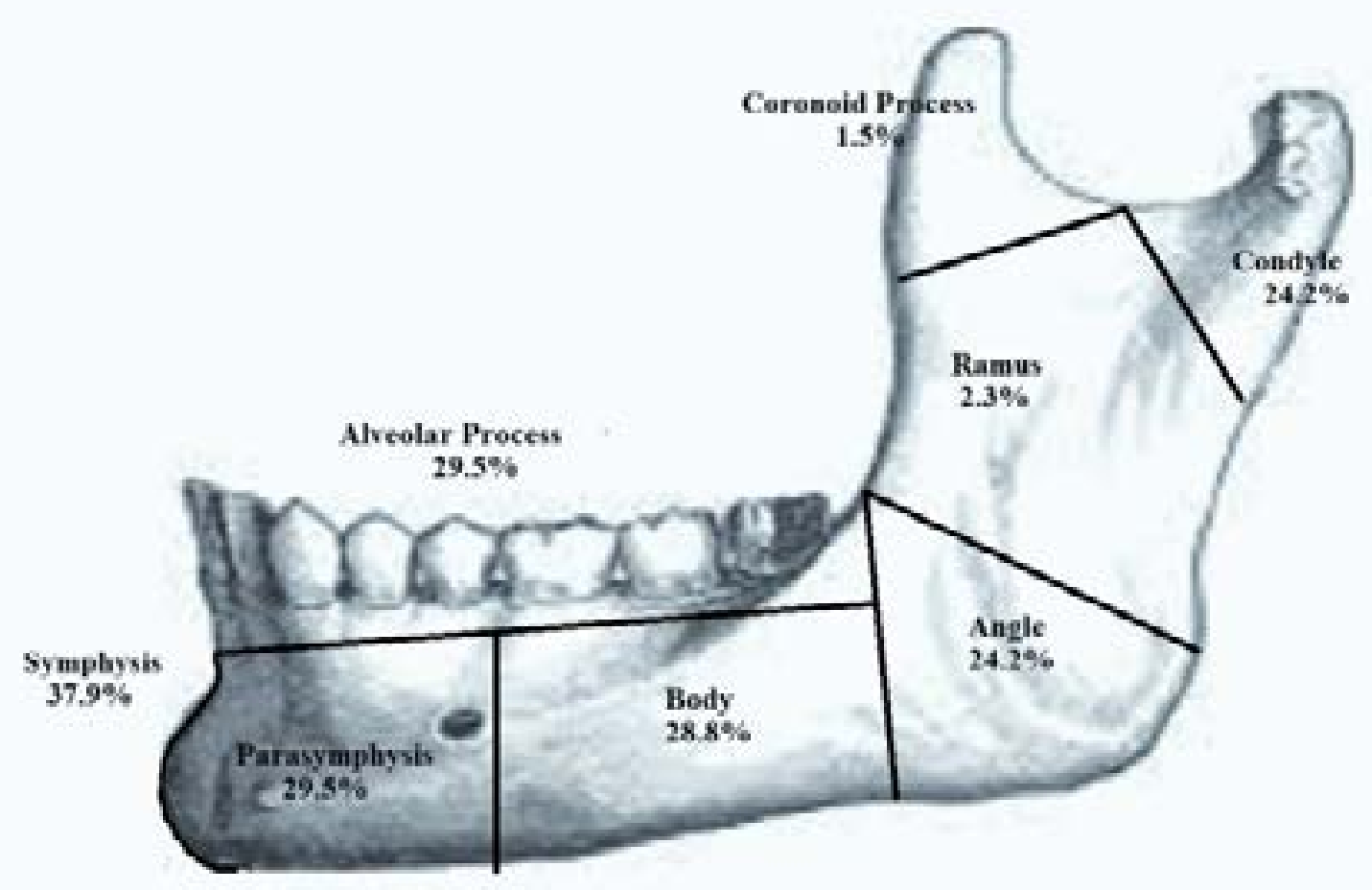

Figure 1: Distribution of anatomical location of 196 fractured site among the 132 patients with mandibular fractures.

A statistically significant association was noted between multiplicity of fractures site with sex, status of the victim during crash and type of helmet used $(p<0.05)$.
Speed, alcohol use, status of the road and age of the victims had no statistically significant association with occurrence of multiple site fractures of the mandible [Table 2]. 
Table 2: Sociodemographic characteristics, and circumstances during crash according to the multiplicity of mandibular fractured sites.

\begin{tabular}{|c|c|c|c|c|}
\hline \multicolumn{4}{|c|}{$\begin{array}{ll}\text { Multiplicity of fractured sites } \\
\end{array}$} & \multirow[b]{2}{*}{ P-value } \\
\hline Variables of $\mathbf{I}$ & terest & & & \\
\hline Sex & $\begin{array}{c}\text { Male } \\
\text { Female }\end{array}$ & $\begin{array}{c}48(40 \%) \\
9(75 \%)\end{array}$ & $\begin{array}{c}72(60 \%) \\
3(25 \%)\end{array}$ & 0.02 \\
\hline Age group & $\begin{array}{c}0-20 \\
21-40 \\
41-60\end{array}$ & $\begin{array}{c}14(56 \%) \\
42(41.6 \%) \\
1(16.7 \%)\end{array}$ & $\begin{array}{c}11(44 \%) \\
59(58.4 \%) \\
5(83.3 \%)\end{array}$ & 0.174 \\
\hline $\begin{array}{l}\text { Alcohol use } \\
\text { by rider }\end{array}$ & $\begin{array}{l}\text { Yes } \\
\text { No }\end{array}$ & $\begin{array}{c}18(45 \%) \\
39(42.4 \%)\end{array}$ & $\begin{array}{c}22(55 \%) \\
53(57.6 \%)\end{array}$ & 0.781 \\
\hline $\begin{array}{l}\text { Status of } \\
\text { victim during } \\
\text { crash }\end{array}$ & $\begin{array}{c}\text { Rider } \\
\text { Pillion passenger } \\
\text { Pedestrian }\end{array}$ & $\begin{array}{c}32(36 \%) \\
19(55.9 \%) \\
6(66.7 \%)\end{array}$ & $\begin{array}{c}57(64 \%) \\
15(44.1 \%) \\
3(33.3 \%)\end{array}$ & 0.046 \\
\hline Use of helmet & $\begin{array}{l}\text { Yes } \\
\text { No }\end{array}$ & $\begin{array}{l}25(48.1 \%) \\
26(36.6 \%)\end{array}$ & $\begin{array}{l}27(51.9 \%) \\
45(63.4 \%)\end{array}$ & 0.203 \\
\hline $\begin{array}{l}\text { Type of } \\
\text { helmet }\end{array}$ & Full face & $14(82.4 \%)$ & $3(17.6 \%)$ & 0.001 \\
\hline $\begin{array}{l}\text { Status of road } \\
\text { maintenance }\end{array}$ & $\begin{array}{l}\text { Half face } \\
\text { Well } \\
\text { Poor }\end{array}$ & $\begin{array}{c}11(31.4 \%) \\
42(41.2 \%) \\
15(50 \%)\end{array}$ & $\begin{array}{c}24(68.6 \%) \\
60(58.8 \%) \\
15(50 \%)\end{array}$ & 0.391 \\
\hline $\begin{array}{l}\text { Speed of } \\
\text { motorcycle } \\
\text { during crash }\end{array}$ & $\begin{array}{c}0-30 \\
31-60 \\
>60\end{array}$ & $\begin{array}{c}6(54.5 \%) \\
36(42.4 \%) \\
15(41.7 \%)\end{array}$ & $\begin{array}{c}5(45.5 \%) \\
49(57.6 \%) \\
21(58.3 \%)\end{array}$ & 0.727 \\
\hline
\end{tabular}

On performing univariate analysis of the risk factors associated with multiple fractures of the mandible, females were $78 \%$ less likely to have multiple fractures compared to males. Moreover, the odds of a non-rider (passenger or pedestrian) to sustain multiple mandibular fractures were $60 \%$ less than those of a rider. The odds of sustaining fractures to multiple sites in victims wearing half-face helmet were 10 times more than those wearing full-face helmet [Table 3]. 
Table 3: Univariate analysis of the risk factors associated with multiple sites of mandibular fracture

\begin{tabular}{lcc}
\hline $\begin{array}{l}\text { Risk Factors for multiple } \\
\text { mandibular fractures }\end{array}$ & $\begin{array}{c}\text { Odds Ratio } \\
(\mathrm{OR})\end{array}$ & $95 \%$ Confidence Interval \\
& 1 & \\
\hline Sex & $0.06-0.86$ \\
$\quad$ Male & 0.22 & \\
$\quad$ Female & & $0.19-0.85$ \\
$\begin{array}{l}\text { Victim Status } \\
\text { Rider }\end{array}$ & 1 & \\
$\quad$ Passenger/Pedestrian & 0.40 & \\
$\begin{array}{l}\text { Type of Helmet } \\
\text { Half face }\end{array}$ & & $0.02-0.41$ \\
$\quad$ Full Face & 1 & \\
\hline
\end{tabular}

Treatment modalities for management of mandibular fractured included alveolar bone splinting Maxillo-Mandibular Fixation (MMF) and Open Reduction and Internal Fixation (ORIF). One hundred and eighteen MMF were performed, out of which 39 (33.1\%) were as part of ORIF. There were a total of 41 procedures of ORIF, of which majority $(39,95.1 \%)$ were done using intra-osseous wire (semi-rigid fixation).

Out of the 32 fractured alveolar bones, $30(93.7 \%)$ were managed by alveolar bone splinting. MMF alone served as definitive treatment for majority of fractured sites with exception of the fractures of angle of mandible, in which majority required ORIF [Table 4].

Table 4: Modality of treatment of mandibular fracture according to the fractured sites.

\section{Management of mandibular fracture}

\begin{tabular}{lcc}
$\begin{array}{l}\text { Maxillo-Mandibular } \\
\text { of the fracture }\end{array}$ & $\begin{array}{c}\text { Open Reduction } \\
\text { and Internal }\end{array}$ & $\begin{array}{c}\text { MMF + ORIF } \\
\text { (semi-rigid fixation) }\end{array}$ \\
& Fixation (MMF) only & Fixation \\
& (ORIF); using \\
& Plates and screws \\
\hline
\end{tabular}

$\begin{array}{lc}\text { Symphysis }(\mathrm{n}=50) & 32(64 \%) \\ \text { Parasymphysis }(\mathrm{n}=39) & 26(72.2 \%) \\ \text { Body }(\mathrm{n}=38) & 29(76.3 \%) \\ \text { Angle }(\mathrm{n}=32) & 14(43.7 \%) \\ \text { Ramus }(\mathrm{n}=3) & 3(100 \%) \\ \text { Condylar }(\mathrm{n}=32) & 30(93.7 \%) \\ \text { Coronoid } & 2(100 \%) \\ \text { process }(\mathrm{n}=2) & \end{array}$

$2(1 \%)$

-

$2(5.3 \%)$

$2(6.3 \%)$

$-$

$2(7.3 \%)$
$16(32 \%)$

$13(27.8 \%)$

$7(18.4 \%)$

$16(50 \%)$

$3(100 \%)$

$2(100 \%)$ 


\section{Discussion}

Motorcycles are the fastest growing sector of motor vehicles worldwide and comprise the majority of all motor vehicles in low- and middle-income countries?. The affordability, maneuverability, and cost-effectiveness of motorcycles make them a popular choice of transport $\mathrm{t}^{10}$. However, the motorcycles are reported to be the most dangerous motor vehicle, because for each mile that vehicle passes, motorcyclists have an 8-fold higher chance of injuries (including the maxillofacial region) compared to those in other types of vehicles ${ }^{11}$.

The predominance of young adults (mean age 27.1 years) and males $(90.9 \% \%)$ in motorcycle crashes in this study support the results of previous studies ${ }^{2,5,8}$. These findings have been attributed to the role played by young adults and men in families. They are the bread earners of the families in several occasions, and that would entail frequent movements from place to place hence increasing their chances of being involved in crashes $^{2}$.

Alcohol has been described to be one of the major risk factors of motorcycle crashes ${ }^{12}$. Its consumption is associated with crashes as it impairs judgement, causes carelessness and loss of concentration as well as over speeding $^{12,13}$. In this study it was found that about $30 \%$ of the motorcycle riders were reported to have been under influence of alcohol prior to the crash. This was higher than what has been reported in some studies ${ }^{9,14}$. The exact frequency of use of alcohol is however not known as majority of the respondents who were either pedestrians or pillion passengers could not tell whether the rider was under influence of alcohol or not. Moreover, some respondents might have lied, as most often, the riders do not reveal the truth about alcohol use.

In this study, $42 \%$ of the motorcyclist were wearing helmets during crash. This was higher than $10 \%$ reported by Bali et al. ${ }^{15}$, but lower than what was reported by Kraus et al. ${ }^{16}$. It was also found that pillion passengers were less likely to wear helmets than riders, and these results are consistent with those of other studies ${ }^{17,18}$. The low proportion of helmet use among passengers may be explained by lack of awareness among the passengers that they are supposed to wear helmet 18 , and also fear of "transmitting" certain skin diseases among pillion passengers who patronize commercial motorcyclists 5 .

The mandible is one of the commonly affected bones during motorcycle crashes ${ }^{19}$, plausibly, because of its prominence. In congruency with findings of Oginni et al. ${ }^{5}$, the findings in this study found that the frequency of mandibular fracture has a trend to decrease antero-posteriorly from the symphyseal region to the condyle. To the contrary, Lima et al..$^{10}$, reported the condyle, followed by symphysis were the commonly affected sites. The symphysis may be prone to fracture during motorcycle crashes because during head on collisions, the central parts of the body are more exposed than the sides. Majority of the victims had fractures in multiple sites, this may be due to the idea that the mandible can be regarded as a single bone reaching both sides, hence, direct fractures on the impact side are often followed by an indirect fracture on the opposite side ${ }^{20}$.

One goal of this study was to evaluate whether a difference existed in the occurrence of severity/multiplicity of mandibular fractures between helmeted versus non-helmeted victims. This investigation showed that, there was no significant difference in occurrence of mandibular fractures between the helmet users and non-users, similar to the findings by Christian et al ${ }^{7}$. One possible explanation for this finding is that majority of the patients used half-face helmets which provided relatively less protection to the mandible. This explanation was further augmented with the findings that the odds of multiple fractures in victims using half-face helmet was higher than those who wore full-face helmets.

The ultimate objective of managing mandibular fractures is to reduce and stabilize the fracture in order to obtain a functional occlusion, and normal anatomy of the jaws and bone ${ }^{21}$. Thus, effective management of mandibular fracture is crucial to restore compromised form and function ${ }^{22}$. Although, open reduction and internal fixation remains the "gold standard" of treatment of maxillofacial fractures, closed reduction by maxillomandibular fixation was the most common form of treatment for mandibular fractures in this study. Similar findings were reported by Adeyemo et al. ${ }^{23}$. Intraosseous wire osteosynthesis was employed for open reduction and internal fixation of mandibular fractures in some cases especially those with unfavorable fractures of angle of mandible. Most cases of ORIF were performed using intra-osseous wires due to limited availability of metal implants (plates and screws) and where available, the cost of treatment was unaffordable to majority of the victims. 


\section{Conclusion}

Mandibular fractures associated with motorcycle crashes commonly occurred in the age group of 20-40 years. Males were affected ten times more than females. Most of the victims were riders during the crash. The symphysis region was the frequently fractured anatomical site. There was no difference in occurrence of mandibular fractures between those who wore and those who did not wear helmets during the crash. Sex of the victim, status of the victim during crash and type of helmet used were strongly associated with multiplicity of fractured sites. Victims wearing half-face helmet were 10 times more likely to have fractures to multiple sites of mandible.

\section{Source(s) of support}

Ministry of Health, Community Development, Gender, Elderly and Children of the United Republic of Tanzania

\section{Acknowledgement}

None.

\section{Conflict of interest}

None.

\section{References}

1. Maliska MC de S, Borba M, Asprino L, de Moraes M, Moreira RWF. Oral and maxillofacial surgery - Helmet and maxillofacial trauma : a 10-year retrospective study. Braz J Oral Sci. 2012;11(2):125-129.

2. Owibingire SS, Kalyanyama BM, Sohal KS. The Pattern of dental injury, incidence of dental caries and dental treatment need among motorcycle crash victims in Tanzania. Int J Dent Heal Sci. 2018;5(1):8-20.

3. Batstone MD, Monsour FNT, Pattel P, Lynham A. The patterns of facial injury suffered by patients in road traffic accidents: A case controlled study. Int J Surg. 2007;5(4):250-254. doi:10.1016/j.ijsu.2006.10.002

4. Chalya PL, Mchembe M, Mabula JB, Kanumba ES, Gilyoma JM. Etiological spectrum , injury characteristics and treatment outcome of maxillofacial injuries in a Tanzanian teaching hospital. J Trauma Manag Outcomes. 2011;5:7.

5. Oginni FO, Ugboko VI, Ogundipe O, Adegbehingbe BO. Motorcycle-related maxillofacial injuries among nigerian intracity road users. J Oral Maxillofac Surg. 2006;64(1):56-62. doi:10.1016/j.joms.2005.09.027

6. Agbor AM, Chinedu AC, Ebot-Tabil B, Naidoo S. Dentofacial injuries in commercial motorcycle acci- dents in Cameroon: Pattern and cost implication of care. Afr Health Sci. 2014;14(1):77-82. doi:10.4314/ahs. v14i1.12

7. Christian JM, Thomas RF, Scarbecz M. The incidence and pattern of maxillofacial injuries in helmeted versus non-helmeted motorcycle accident patients. J Oral Maxillofac Surg. 2014;72(12):2503-2506. doi:10.1016/j. joms.2014.07.015

8. Miki N, Martimbianco ALC, Hira LT, Lahoz GL, Fernandes HJA, Dos Reis FB. Profile of trauma victims of motorcycle accidents treated at hospital São Paulo. Acta Ortop Bras. 2014;22(4):219-222. doi:10.1590/141378522014220400642

9. Erdogan MO, Sogut O, Colak S, Ayhan H, Afacan MA, Satilmis D. Role of Motorcycle Type in Motorcycle Crush Injuries. Emerg Med Int. 2013;2013.

10. Lima SM, Santos SE, Kluppel LE, Asprino L, Moreira RWF, De Moraes M. A Comparison of motorcycle and bicycle accidents in oral and maxillofacial trauma. J Oral Maxillofac Surg. 2012;70(3):577-583. doi:10.1016/j.joms.2011.03.035

11. Cavalcanti AL, Ferreira FHC, Olinda RA. Motorcycle-Related Cranio-Maxillofacial Injuries Among Brazilian Children and Adolescents. Biomed Pharmacol J. 2017;10(4).

12. Alicioglu B, Yalniz E, Eskin D, Yilmaz B. Injuries associated with motorcycle accidents. Acta Orthop Traumatol Turc. 2008;42(2):106-111. doi:10.3944/ AOTT.2008.42.2.106

13. Singaram M, G SV, Udhayakumar RK. Prevalence, pattern, etiology, and management of maxillofacial trauma in a developing country: a retrospective study. J Korean Assoc Oral Maxillofac Surg. 2016;42:174-181. doi:10.5125/jkaoms.2016.42.4.174

14. Karau P, Ogeng J, Okoro D, Muia M, Saumu M. Risk Factor Profile of Motorcycle Crash Victims in Rural Kenya. Ann Afri Surg. 2015;12(1):4-8.

15. Bali R, Sharma P, Garg A, Dhillon G. A comprehensive study on maxillofacial trauma conducted in Yamunanagar, India. J Inj Violence Res. 2013;5(2):108116. doi:10.5249/jivr.v5i2.331

16. Kraus JF, Rice TM, Peek-Asa C, McArthur DL. Facial trauma and the risk of intracranial injury in motorcycle riders. Ann Emerg Med. 2003;41(1):18-26. doi:10.1067/mem.2003.1

17. Hung D V., Stevenson MR, Ivers RQ. Prevalence of helmet use among motorcycle riders in Vietnam. Inj Prev. 2006;12(6):409-413. doi:10.1136/ip.2006.012724

18. Kauky CG, Kishimba RS, Urio LJ, Abade AM, Mghamba JM. Prevalence of helmet use among motor- 
cycle users in Dar Es Salaam, Tanzania. Pan Afric Med J. 2015;20:438. doi:10.11604/pamj.2015.20.438.5659

19. Hashim H, Iqbal S. Motorcycle accident is the main cause of maxillofacial injuries in the Penang Mainland, Malaysia. Dent Traumatol.2011;27(1):19-22. doi:10.1111/ j.1600-9657.2010.00958.x

20. Chrcanovic BR, Abreu MHNG, Freire-Maia B, Souza LN. 1,454 mandibular fractures: A 3-year study in a hospital in Belo Horizonte, Brazil. J Cranio-Maxillofacial Surg. 2012;40(2):116-123. doi:10.1016/j. jcms.2011.03.012
21. Sohal KS, Moshy J. Management of Mandibular Fracture in a Peripheral Health Setting with Limited Resources: a Case Report. East Cent Afr J Surg. 2014;19(2):131-135.

22. Meaike JD, Hollier LH. Trauma \& Treatment Updates in Facial Fracture Management. J Trauma Treat. 2015;4(4):274. doi:10.4172/2167-1222.1000274

23. Adeyemo WL, Ladeinde AL, Ogunlewe MO, James O. Trends and characteristics of oral and maxillofacial injuries in Nigeria: a review of the literature. Head Face Med. 2005;1:7-15. 